\title{
Ultrasound of the Hypoglossal Nerve in the Neck: Visualization and Initial Clinical Experience with Patients
}

\author{
(D). Meng, (D)L.F. Reissig, (DC.-H. Tzou, DK. Meng, (D) W. Grisold, and (DW. Weninger
}

\begin{abstract}
BACKGROUND AND PURPOSE: The hypoglossal nerve, providing motor innervation for the tongue, can be affected in many diseases of the neck and skull base, leading to dysarthria, dysphagia, and ultimately atrophy of the tongue. We determined the feasibility of direct visualization of the hypoglossal nerve in the neck with ultrasound, testing this technique on healthy volunteers and evaluating it in clinical practice.
\end{abstract}

MATERIALS AND METHODS: The study consisted of 4 parts: first, ultrasound-guided perineural ink injections along the course of the hypoglossal nerve at 24 sides of 12 fresh, nonembalmed cadaver necks. Subsequently, the specimens were dissected to confirm the correct identifcation of the nerve. The second part was examination of healthy volunteers with ultrasound and measurement of cross-sectional areas for generating reference data. The third part was scanning of healthy volunteers by 2 resident physicians with little and intermediate experience in ultrasound. Fourth was examination with ultrasound of patients with motor symptoms of the tongue.

RESULTS: The hypoglossal nerve was correctly identified bilaterally in all cadaveric specimens (24/24) and all volunteers (33/33). The cross-sectional area ranged from 1.9 to $2.1 \mathrm{~mm}^{2}$. The resident physicians were able to locate the nerve in 19 of 22 cases, demonstrating that locating the nerve is reproducible and feasible even with intermediate experience in ultrasound. Finally, alterations of the hypoglossal nerve in disease states could be depicted.

CONCLUSIONS: Direct, reliable, and reproducible visualization of the extracranial hypoglossal nerve with ultrasound is feasible.

ABBREVIATION: US $=$ ultrasound

$\mathbf{T}$ he hypoglossal nerve provides motor innervation for the entire tongue with the exception of the palatoglossal muscle. The nerve leaves the medulla oblongata between the olive and the pyramid in the preolivary groove, passes through the premedullary cistern, and exits the skull through the hypoglossal canal. Inferior to the skull base, the nerve descends lateral to the carotid artery, traveling with the glossopharyngeal, vagal, and accessory nerves; the carotid artery; and the internal jugular vein within the carotid space. At the level of the mandibular angle, the nerve courses anteriorly, caudal to the posterior belly of the digastric muscle, toward the hyoid bone. Here, the nerve enters the submandibular space, passes between the mylohyoid and the hyo-

Received April 27, 2015; accepted after revision May 22.

From the Departments of Radiology (S.M.), Ear, Nose, and Throat Diseases (K.M.), and Neurology (W.G.), KFJ Hospital, Vienna, Austria; and Center for Anatomy and Cell Biology (S.M., L.F.R., W.W.) and Division of Plastic and Reconstructive Surgery (C.-H.T.), Department of Surgery, Medical University of Vienna, Vienna, Austria.

Please address correspondence to Stefan Meng, MD, Center for Anatomy and Cell Biology, Währinger Str 13, 1090 Vienna, Austria; e-mail: stefan.meng@meduniwien. ac.at

http://dx.doi.org/10.3174/ajnr.A4494 glossal muscles into the sublingual space, and finally enters the body of the tongue. ${ }^{1}$

A lesion of the hypoglossal nerve can cause dysarthria, dysphagia, and tongue paralysis, and unilateral atrophy of the tongue muscles may result. Denervation of the tongue can be secondary to radiation therapy due to formation of fibrotic tissue around the nerve, infection, lymphadenopathy, tumor entrapping or infiltrating the nerve, neurogenic tumors arising within the nerve, or trauma, with iatrogenic trauma resulting from carotid endarterectomy, neck dissection, or tonsillectomy being among the more common causes of hypoglossal nerve dysfunction. There are also reports of carotid and vertebral artery dissections leading to hypoglossal nerve injury. ${ }^{2-18}$ In a large case series of hypoglossal nerve palsies, the site of the lesion could not be localized in $6 \%$. ${ }^{9}$

In the radiologic diagnostic work-up, a segmental imaging approach is advised. ${ }^{19-21}$ The medullary, cisternal, and skull base segments can be well examined with the existing protocols of MR imaging and CT. In the carotid and submandibular spaces, these imaging modalities are also recommended, but the nerve itself is usually not depicted. ${ }^{19,20,22}$ We are not aware of any study of the 

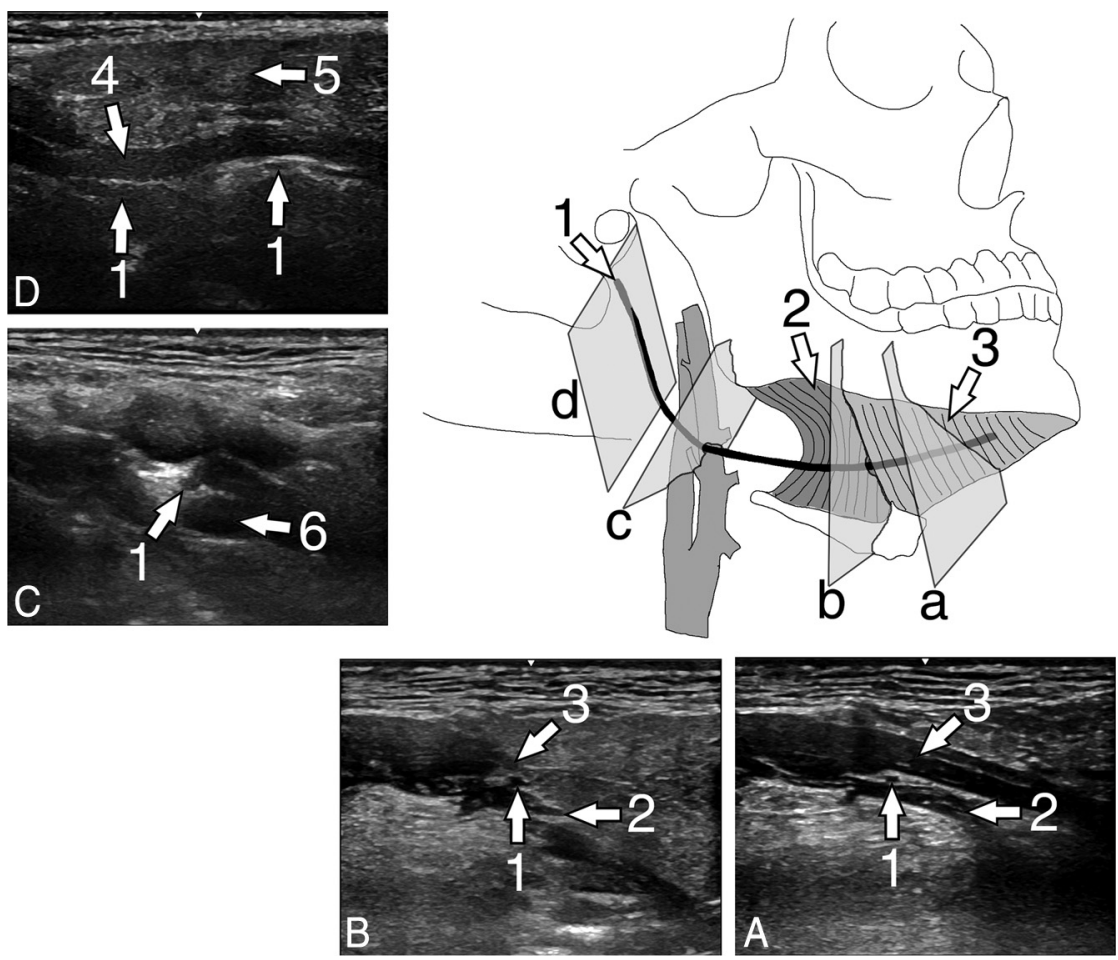

FIG 1. Illustration of the hypoglossal nerve with exemplary US scans of the hypoglossal nerve of a healthy volunteer. $A$, Transversal scan at the floor of the mouth in a coronal body plane. $B$, Transversal scan at the posterior rim of the hyoglossal muscle in a coronal body plane. C, Transversal scan in a paracoronal body plane at the crossing of the nerve with the external carotid artery. $D$, Longitudinal scan at the carotid space in a paracoronal body plane. $1=$ hypoglossal nerve, 2 = hyoglossal muscle, 3 = mylohyoid muscle, 4 , = stylohyoid and styloglossal muscles, $5=$ parotid gland, $6=$ external carotid artery .

feasibility of the direct visualization of the extracranial hypoglossal nerve, though ultrasound (US) has been increasingly used to visualize peripheral nerves to diagnose and localize pathologies affecting them. ${ }^{23,24}$

The aim of our study was to test the feasibility of direct visualization of the extracranial hypoglossal nerve with US in fresh cadavers, healthy volunteers, and patients with a suspected lesion of the hypoglossal nerve. A secondary objective was to provide data on the cross-sectional area of the hypoglossal nerve in our volunteer sample as a reference.

\section{MATERIALS AND METHODS}

Our study consisted of 4 parts: In the first part, the cadaveric study, we examined the technical feasibility of visualization of the extracranial hypoglossal nerve with US in fresh human specimens. In the second part, the volunteer study, we examined individuals and performed measurement of the nerve cross-sectional areas. In the third part, the reproducibility study, we evaluated whether 2 resident physicians with little and intermediate experience in US were capable of locating the hypoglossal nerve in a second group of healthy volunteers. The last part was a clinical evaluation, in which we performed US scans of patients with a known pathology of the neck and tongue palsy or, in one case, screened for neurofibromatosis. We visualized the pathology and the affected hypoglossal nerve. All 4 parts of this study were performed according to the regulations of the local ethics committees.

\section{Cadaveric Study}

For this study, we examined 24 neck sides from fresh, nonembalmed cadavers of 5 women and 7 men, with a mean age of $78.25 \pm 11.23$ years (median, 79 years; maximum, 97 years; minimum, 58 years). They donated their bodies to the Department of Anatomy. According to the medical records, they had no neuromuscular or neck and throat disease.

All cadaver specimens were scanned with a portable US system (LOGIQ e; GE Healthcare, Milwaukee, Wisconsin) by using a linear wide-band array transducer with an imaging frequency of 4.2-13 MHz (L4-12t-RS, LOGIQ e; GE Healthcare). A radiologist with 8 years of experience in clinical and interventional ultrasound performed US scans and US-guided injections.

The cadaver was placed in a supine position, with the neck in maximum extension. Then the US transducer was positioned at the sublingual space aligned parallel to the coronal body plane (Fig $1 D)$. The hypoglossal nerve was localized as an oval hypoechoic structure in the space between the mylohyoid and the hyoglossal muscles. From this starting position, the nerve was tracked medially into the tongue and laterally to the carotid space with slight adjustments of the scan plane (Fig $1 C$, $-B)$. Within the carotid space, the hypoglossal nerve was tracked further as it turns cranially and courses parallel to the carotid vessels to the skull base (Fig $1 B,-A$ ). Along the course from the sublingual space to the end of the carotid space at the skull base, in steps of 1-2 cm, a 23-ga syringe needle aligned parallel to the US scan plane was advanced from the skin to the nerve. The needle tip was positioned at the perineural sheath of the hypoglossal nerve. There, a small amount (approximately $0.01 \mathrm{~mL}$ ) of India ink diluted 1:10 with saline solution and thickened with Nutilis (Nutricia, Erlangen, Germany) was injected. The ink was thickened to minimize the spread of the color. During the US scan, the injected ink was digitally documented as small pockets of hypoechoic fluid around the nerve.

Immediately after the injection procedure, the cadaver was dissected by 2 experienced anatomists. Using surgical scalpels and forceps, they exposed the hypoglossal nerve from the entry of the nerve into the tongue to the region inferior to the skull base. The distribution of the ink was photo-documented.

\section{Volunteer Study}

Thirty-three healthy volunteers (17 men, 16 women) without any known neuromuscular or neck and throat disease, with an average age of $44.9 \pm 11.85$ years (median, 43 years; maximum, 70 years; minimum, 27 years) were recruited from the authors' families and the hospital staff. Written informed consent was obtained from all volunteers. Using the same examination protocol and US hard- 
ware as in the cadaveric study, the same radiologist scanned the test individuals.

Cross-sectional areas of the hypoglossal nerve were measured at 2 distinct locations at both sides of the volunteers' necks. The first position was at the posterolateral border of the mylohyoid muscle (Fig 1C). Here, the US transducer was rotated to a position transverse to the long axis of the hypoglossal nerve. A still image of the cross-section of the nerve was stored. The second position was at the crossing of the nerve with the external carotid artery (Fig $1 B)$. Here again, the US scanning plane was aligned transverse to the long axis of the nerve, and an US still image was stored. The actual measurement of the cross-sectional area at these 2 positions was performed after the scanning procedure on a personal computer by using the software ImageJ (National Institutes of Health, Bethesda, Maryland) for greater ease of use.

\section{Reproducibility Study}

A second group of 11 healthy volunteers (7 women and 4 men) without any known neuromuscular or neck and throat disease, with an average age of $48 \pm 10.13$ years (median, 4 years; maximum, 61 years; minimum, 27 years) was recruited from the hospital staff. Written informed consent was obtained from all volunteers.

After a short introduction of a few minutes on the scanning technique, in particular by using Fig 1, an ear, nose, and throat diseases resident physician with little experience in US ( $<1$ year) and a radiology resident physician with intermediate experience in US (4 years) scanned the test individuals by using the same examination protocol and US hardware as in the cadaveric study.

The assigned task was to locate the hypoglossal nerve at the 2 locations defined in the volunteer study described above. These were at the posterolateral border of the mylohyoid muscle (Fig $1 C$ ) and at the crossing of the nerve with the external carotid artery (Fig 1B).

A total scanning time limit of 5 minutes for each volunteer neck side was set. The primary investigator checked the results presented by the resident physicians.

\section{Clinical Evaluation}

Between 2014 and 2015, we examined 6 patients with hypoglossal nerve palsy and a prior operation of the hypoglossal nerve and a patient with neurofibromatosis, who were referred to our department. These patients ( 4 men and 2 women) with a mean age of 54.3 years were examined with the same US hardware as described in the cadaveric study. US still images were recorded. The US findings were correlated with the known clinical history and course.

\section{RESULTS}

\section{Cadaveric Study}

In all specimens (24/24), we could identify the hypoglossal nerve within the slit between the mylohyoid and hyoglossal muscles in the sublingual space by using US. From this scanning position, it was also possible to track the nerve medially until it entered the tongue, laterally into the carotid space, and further cranially along the carotid arteries accompanied by the vagal, glossopharyngeal, and accessory nerves (Fig 1). The most cranial part of the course

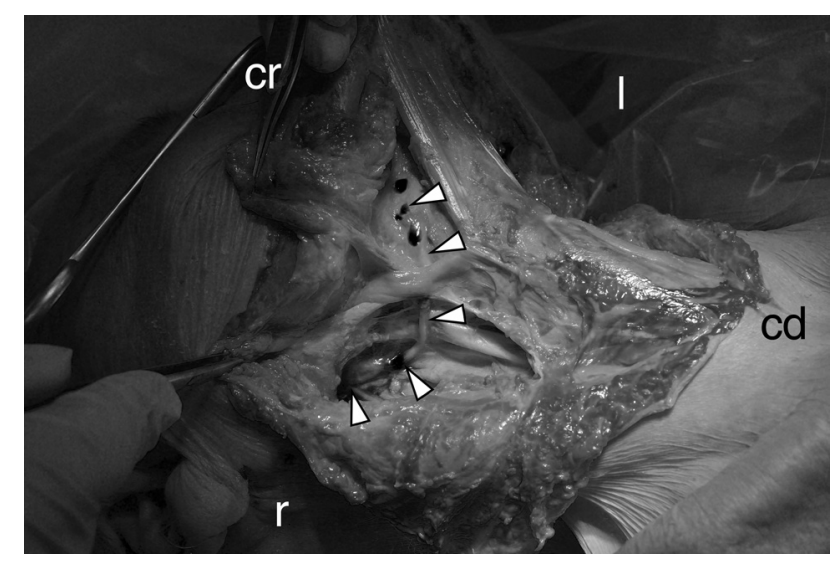

FIG 2. Dissection situs of the right side of a neck. View from ventrolateral. Note the exposed hypoglossal nerve (arrowheads) with dark ink markings along its course. Cr indicates cranial; cd, caudal; r, right; l, left.

within the carotid space, just beneath the skull base, could not be visualized completely because it was deep within the neck covered by the styloid and mastoid processes. In the dissection, the injected ink was found exclusively at the perineural sheath of the hypoglossal nerve (Fig 2). No ink was found inside the nerve or within any other structure of the neck but the perineural sheath of the hypoglossal nerve.

\section{Volunteer Study}

Following the protocol developed in the prior cadaveric study, we were able to visualize the hypoglossal nerve in all volunteers (33/ 33). It was possible to take reference measurements of the crosssectional areas of the hypoglossal nerve at the posterolateral rim of the mylohyoid muscle and at the crossing with the external carotid artery in all specimens. Our measurement results are presented in Table 1.

We encountered minor difficulties tracking the hypoglossal nerve with US throughout its course due to the lower image quality in persons with beards and due to the limited space for US transducer movements in volunteers with large collar sizes and short necks. However, we were able to locate the nerve and perform the required measurements.

\section{Reproducibility Study}

Both resident physicians were able to locate the hypoglossal nerve in 19 of 22 neck sides. The radiology examiner with intermediate experience in US failed to locate the hypoglossal nerve in only 1 neck side. The otorhinolaryngologist with little experience in US failed to find the nerve in 3 neck sides within the set time limit of 5 minutes per neck side. Both examiners extensively used the color Doppler mode. For both examiners, this facilitated distinguishing the nerve from small blood vessels because both structures may have a similar morphology in gray-scale ultrasound.

\section{Clinical Evaluation}

Our US examination revealed a variety of pathologies. Our sample included 6 patients with conditions such as iatrogenic scar tissue around a nerve (Fig 3), nerve infiltration by oropharyngeal carcinoma (Fig 4), surgical end-to-side nerve coaptation (Fig 5), partial nerve transfer, and a neurofibroma (Fig 6). Medical his- 


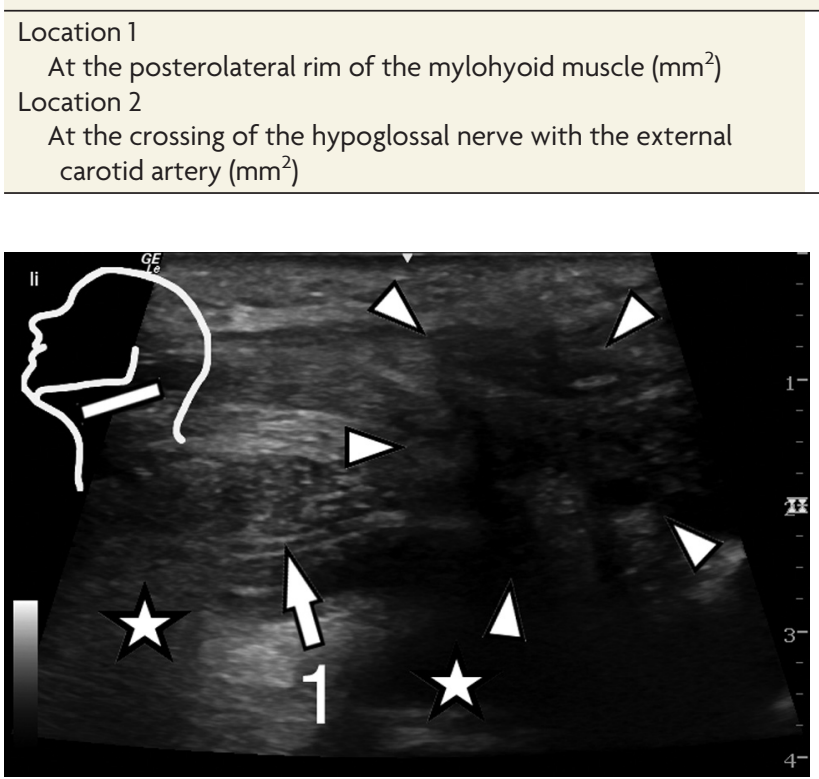

FIG 3. Parasagittal US scan at the floor of the mouth of patient 1 (Table 2). Note the hypoglossal nerve entering the region with extensive scar tissue after a neck dissection operation. Inset: position of the US transducer; 1 = hypoglossal nerve, asterisks = body of the tongue, arrowheads $=$ scar tissue.

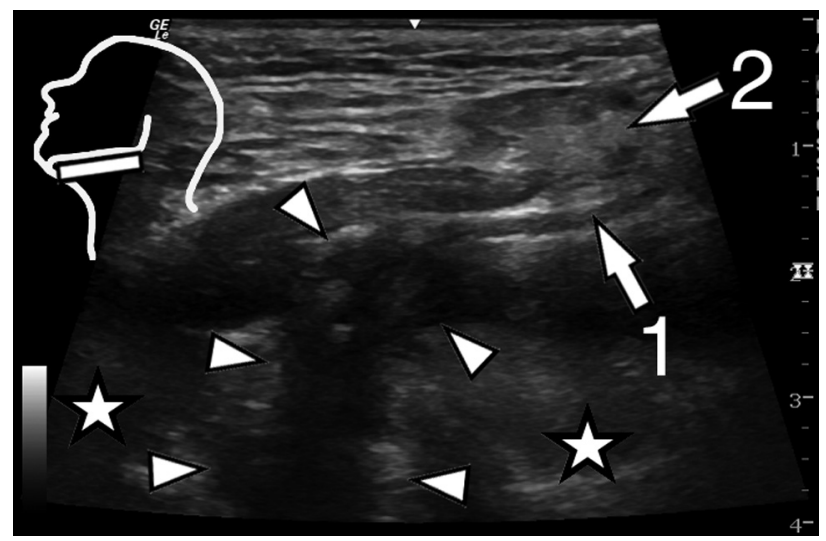

FIG 4. Parasagittal US scan at the floor of the mouth of patient 2 (Table 2). The hypoglossal nerve is directly infiltrated by a squamous cell carcinoma of the tongue base. Inset: position of the US transducer; 1 = hypoglossal nerve, 2 = submandibular gland, asterisks = body of the tongue, arrowheads = squamous cell carcinoma of the tongue base.

tory, US findings, and the assumed diagnosis of our patients are listed in Table 2.

In all patients, the extracranial course of the nerve and the pathologies affecting the nerve could be visualized. Image quality was lower in patients with prior operations and subsequent extensive scar tissue in the scanned region.

\section{DISCUSSION}

Paralysis of the tongue can be a symptom of a heterogeneous spectrum of pathologies, and imaging of the potentially affected regions in the central and peripheral nervous system is an essential element of the diagnostic work-up. In case of a suspected lesion of
$1.9(2,0.6,3,0.8)$

$2.1(1.7,0.6,3,0.8)$
SD, Maximum, Minimum)

$1.9(2,0.6,4,1)$

$2.1(2.1,0.5,3.4,1.1)$

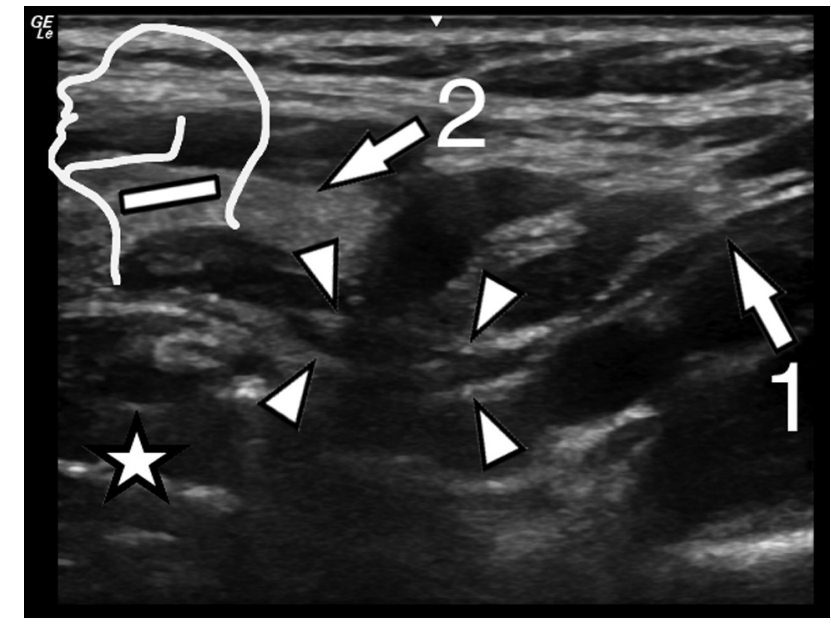

FIG 5. Parasagittal US scan at the carotid space of patient 3 (Table 2). Anterior to the carotid space the hypoglossal nerve is thickened focally after a facial nerve end-to-side coaptation. Inset: position of the US transducer; 1 = hypoglossal nerve, 2 = submandibular gland, asterisk = body of the tongue, arrowheads = coaptation site.

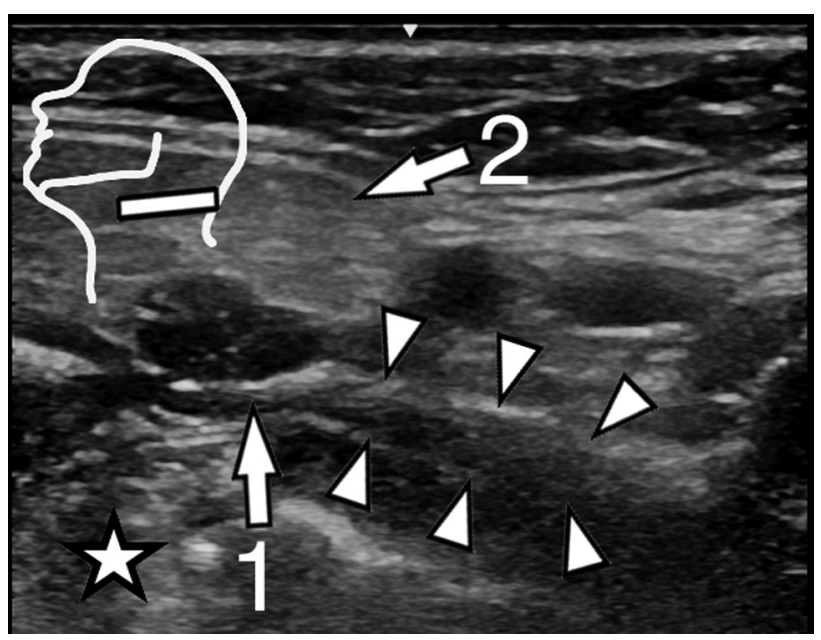

FIG 6. Parasagittal US scan at the carotid space of patient 6 (Table 2). The hypoglossal nerve is thickened markedly in the carotid space due to formation of a fibroma. Inset: position of the US transducer; $1=$ hypoglossal nerve, 2 = submandibular gland, asterisk = body of the tongue, arrowheads = fibroma.

the hypoglossal nerve, radiologic standards have been established. The medullary, cisternal, and skull base segments of the hypoglossal nerve course are examined with CT and MR imaging according to the strengths of these imaging modalities in imaging softtissue or bony structures. For the neck segment of the hypoglossal nerve, CT and MR imaging have also been advocated as the primary imaging modalities. ${ }^{19-21}$ Here, the hypoglossal nerve is assessed indirectly by delineating the muscles innervated by the 
Table 2: Summary of patient histories and US findings

\begin{tabular}{|c|c|c|c|c|c|}
\hline No. & $\begin{array}{l}\text { Age } \\
\text { (yr) }\end{array}$ & Sex & History & Clinical Details on Referral & US findings \\
\hline 1 & 50 & M & $\begin{array}{l}\text { Squamous cell carcinoma of the tonsil, neck } \\
\text { dissection }\end{array}$ & Hypoglossal nerve palsy & Scar tissue around the nerve (Fig 3) \\
\hline 2 & 72 & M & Squamous cell carcinoma of the tongue base & Hypoglossal nerve palsy & Tumor infiltration of the nerve (Fig 4) \\
\hline 3 & 33 & $\mathrm{~F}$ & $\begin{array}{l}\text { Facial nerve end-to-side coaptation to the } \\
\text { hypoglossal nerve after tongue palsy after } \\
\text { cerebellopontine angle tumor resection }\end{array}$ & Tongue paresis & $\begin{array}{l}\text { Nerve coaptation site with focal } \\
\text { hypoglossal nerve thickening (Fig 5) }\end{array}$ \\
\hline 4 & 68 & $\mathrm{~F}$ & $\begin{array}{l}\text { Partial hypoglossal nerve transfer for facial } \\
\text { nerve reconstruction after malignant } \\
\text { parotid gland tumor resection }\end{array}$ & Tongue weakness & $\begin{array}{l}\text { Nerve transfer site with focal thickening } \\
\text { and fibrosis }\end{array}$ \\
\hline 5 & 48 & M & $\begin{array}{l}\text { Squamous cell carcinoma of the tonsil, neck } \\
\text { dissection, radiotherapy, chemotherapy }\end{array}$ & Hypoglossal palsy & $\begin{array}{l}\text { Scar tissue entrapment of the hypoglossal } \\
\text { nerve }\end{array}$ \\
\hline 6 & 55 & M & Neurofibromatosis & Screening & Neurofibroma (Fig 6) \\
\hline
\end{tabular}

nerve and by detecting potential pathologies that are in the vicinity of the expected course of the nerve. Muscle atrophy or muscle denervation changes can indirectly indicate pathology of the hypoglossal nerve, but they are not direct proof. Furthermore, small lesions and pathologic processes originating from the hypoglossal nerve itself may remain undetected.

So far, US has been described as insufficient to give useful information concerning the hypoglossal nerve. ${ }^{19}$ Hence, a reliable imaging protocol for the direct visualization of the nerve has not yet been established, to our knowledge. In the cadaveric study, we developed and verified an US imaging protocol for the reliable visualization of the extracranial hypoglossal nerve, with the exception of the segment directly beneath the hypoglossal canal. We applied this protocol in healthy volunteers and patients.

Although there are many nerves and nerve-like structures in the neck, our ink injections and subsequent dissections show that the nerve can be correctly identified and traced with US. The minor US scanning difficulties we encountered during the examination of healthy volunteers and patients are generally known problems in head and neck US. A large patient collar size and a short neck impede transducer movements and could require the use of lower US transducer frequencies and thus lead to a lower image resolution. Typically, a generally lower US image quality results from beards, prior operations, and prior radiation therapy.

It was possible to visualize the extracranial portion of the hypoglossal nerve in all cadaveric specimens, volunteers, and patients. The only exception was an approximately 1-cm-long segment of the hypoglossal nerve just beneath the external opening of the hypoglossal canal. Here, the US scan was blocked by the styloid and mastoid processes, and we could not develop an alternative sonographic window. From our point of view, this limitation can only be overcome with other image modalities such as CT and/or MR imaging.

The US examinations in the first, second, and fourth part of this study were performed by the highly experienced primary investigator. Physicians with little and intermediate experience in US could locate the hypoglossal nerve in $>86 \%$ and $>95 \%$ of cases, respectively, however, after a brief training of a few minutes. Thus, we are confident that a focused examination of the hypoglossal nerve with US is feasible in clinical routine. As noted in the observation of the resident physicians' scanning, we strongly rec- ommend the use of color Doppler because it seems to facilitate the perception of the hypoglossal nerve position.

A notable shortcoming of our study design is the retrospective character of the clinical part in combination with the low number of cases with hypoglossal nerve pathologies. Nevertheless, primary hypoglossal nerve pathologies are rare, and the focus of our study was to demonstrate the feasibility of visualizing the hypoglossal nerve in different settings. A prospective clinical trial evaluating US versus CT and MR imaging is the next logical step, and we are planning such a study.

In the examination of our patients, all alterations of the nerve itself were focal thickenings and easy to perceive; thus, no comparisons with reference nerve diameters were necessary. Given that some pathologies, for example polyneuropathies, might lead to nerve thickening or thinning over a long segment, ${ }^{25-27}$ in such cases, reference data might be helpful in detecting the pathology. The marginally smaller cross-sectional area of the hypoglossal nerve at the distal measurement point ( 1.9 versus $2.1 \mathrm{~mm}^{2}$ ) can be explained by the branching of the ansa cervicalis.

A radiologic imaging protocol can only be successfully introduced in daily hospital routine if the necessary device is part of the standard equipment. In our study, we used US hardware that is relatively inexpensive and widely available. Furthermore, identifying the hypoglossal nerve between the mylohyoid and hyoglossal muscles is simple. Following our protocol, US can be easily used to assess the extracranial hypoglossal nerve and can complement existing imaging algorithms.

\section{CONCLUSIONS}

We demonstrated that with US, it is possible for even relatively inexperienced examiners to reliably and directly visualize most of the extracranial course of the hypoglossal nerve. We also present reference measurements of the cross-sectional area of the hypoglossal nerve. In a small group of patients, we depicted structural alterations of the nerve and of its immediate surroundings resulting from pathologies and prior operations.

\section{ACKNOWLEDGMENTS}

We thank Muna Nourafza, MD, for her valuable comments during the preparation of the article. 
Disclosures: Wolfgang Weninger-UNRELATED: Grants/Grants Pending: Wellcome Trust, UK (Deciphering the Mechanisms of Developmental Disorders); Payment for Lectures (including service on Speakers Bureaus): IMC-Krems, FH-St Pölten, FH-CampusWien.

\section{REFERENCES}

1. Standring S. Gray's Anatomy: The Anatomical Basis of Clinical Practice. Edinburgh: Churchill Livingstone; 2008

2. Andrioli G, Rigobello L, Mingrino S, et al. Tapia's syndrome caused by a neurofibroma of the hypoglossal and vagus nerves: case report. J Neurosurg 1980;52:730-32 CrossRef Medline

3. Cheng VS, Schultz MD. Unilateral hypoglossal nerve atrophy as a late complication of radiation therapy of head and neck carcinoma: a report of four cases and a review of the literature on peripheral and cranial nerve damages after radiation therapy. Cancer 1975;35: 1537-44 CrossRef Medline

4. Cunningham EJ, Bond R, Mayberg MR, et al. Risk of persistent cranial nerve injury after carotid endarterectomy. J Neurosurg 2004; 101:445-48 CrossRef Medline

5. Ferguson GG, Eliasziw M, Barr HW, et al. The North American Symptomatic Carotid Endarterectomy Trial: surgical results in 1415 patients. Stroke 1999;30:1751-58 CrossRef Medline

6. Friedman L, Eisenberg AA. Neurofibroma of the hypoglossal nerve. Ann Surg 1935;101:834-38 CrossRef Medline

7. Junquera L, Gallego L. Images in clinical medicine: denervation atrophy of the tongue after hypoglossal-nerve injury. $N$ Engl J Med 2012;367:156 CrossRef Medline

8. Karvounaris DC, Symeonidis N, Triantafyllou A, et al. Ectopic parathyroid adenoma located inside the hypoglossal nerve. Head Neck 2010;32:1273-76 CrossRef Medline

9. Keane JR. Twelfth-nerve palsy: analysis of $\mathbf{1 0 0}$ cases. Arch Neurol 1996;53:561-66 CrossRef Medline

10. Kum YS, Kim JK, Cho $\mathrm{CH}$, et al. Intraneural reticular perineurioma of the hypoglossal nerve. Head Neck 2009;31:833-37 CrossRef Medline

11. Lin YS, Jen YM, Lin JC. Radiation-related cranial nerve palsy in patients with nasopharyngeal carcinoma. Cancer 2002;95:404-09 CrossRef Medline

12. Mahadevappa K, Chacko T, Nair AK. Isolated unilateral hypoglossal nerve palsy due to vertebral artery dissection. Clin Med Res 2012;10: 127-30 CrossRef Medline

13. Mohanty SK, Barrios M, Fishbone $\mathrm{H}$, et al. Irreversible injury of cranial nerves 9 through 12 (Collet-Sicard syndrome): case report. J Neurosurg 1973;38:86-88 CrossRef Medline

14. Mokri B, Silbert PL, Schievink WI, et al. Cranial nerve palsy in spontaneous dissection of the extracranial internal carotid artery. $\mathrm{Neu}$ rology 1996;46:356-59 CrossRef Medline

15. Stricker T, Steinlin M, Willi UV, et al. Hypoglossal nerve palsy associated with deep cervical lymphadenopathy. Neurology 1998;50: 1926-27 CrossRef Medline

16. Tong Y. Role of duplex ultrasound in the diagnosis and assessment of carotid body tumour: a literature review. Intractable Rare Dis Res 2012;1:129-33 CrossRef Medline

17. Williamson J, Leopold G, Prabhu V, et al. Successful treatment of a rare metastatic malignant carotid body tumour in a young adult, with conservative surgery and local radiotherapy. J Laryngol Otol 2012;126:428-31 CrossRef Medline

18. Sharp CM, Borg HK, Kishore A, et al. Hypoglossal nerve paralysis following tonsillectomy. J Laryngol Otol 2002;116:389-91 CrossRef Medline

19. Alves P. Imaging the hypoglossal nerve. Eur J Radiol 2010;74:368-77 CrossRef Medline

20. La'porte SJ, Juttla JK, Lingam RK. Imaging the floor of the mouth and the sublingual space. Radiographics 2011;31:1215-30 CrossRef Medline

21. Thompson EO, Smoker WR. Hypoglossal nerve palsy: a segmental approach. Radiographics 1994;14:939-58 CrossRef Medline

22. Sharma B, Dubey P, Kumar S, et al. Isolated unilateral hypoglossal nerve palsy: a study of 12 cases. J Neurol Neurosci 2010;2:5

23. Lieba-Samal D, Pivec C, Platzgummer H, et al. High-resolution ultrasound for diagnostic assessment of the great auricular nerve: normal and first pathologic findings. Ultraschall Med 2014 May 13. [Epub ahead of print] CrossRef

24. Park JK, Jeong SY, Lee JH, et al. Variations in the course of the cervical vagus nerve on thyroid ultrasonography. AJNR Am J Neuroradiol 2011;32:1178-81 CrossRef Medline

25. Weiss MD, Oakley JC, Meekins GD. Hypoglossal neuropathy in Lewis-Sumner syndrome masquerading as motor neuron disease. Neurology 2006;67:175-76 CrossRef Medline

26. Winter WC, Juel VC. Hypoglossal neuropathy in hereditary neuropathy with liability to pressure palsy. Neurology 2003;61:1154-55 CrossRef Medline

27. Zaidman CM, Al-Lozi M, Pestronk A. Peripheral nerve size in normals and patients with polyneuropathy: an ultrasound study. Muscle Nerve 2009;40:960-66 CrossRef Medline 